\title{
Phosphonium ionic liquids as lubricants for aluminium-steel
}

\author{
A. E. Somers ${ }^{1}$, P. C. Howlett ${ }^{1,2}$, J. Sun ${ }^{1,2}$, D. R. MacFarlane ${ }^{2}$ \\ $\&$ M. Forsyth ${ }^{1}$ \\ ${ }^{I}$ Department of Materials Engineering, Monash University, \\ Australia \\ ${ }^{2}$ School of Chemistry, Monash University, Australia
}

\begin{abstract}
The performance of a series of novel room temperature ionic liquids (ILs) based on the trihexyl(tetradecyl)phosphoniumcation $\left(\mathrm{P}_{66614}{ }^{+}\right)$and a number of novel anions have been studied in pin-on-disk tests using a 100Cr6 steel ball on AA2024 aluminium disks. The anions coupled to the $\left(\mathrm{P}_{66614}{ }^{+}\right)$cation include diphenyl phosphate (DPP-), dibutyl phosphate (DBP-), bis (2,4,4-trimethyl pentyl) phosphinate $\left(\mathrm{M}_{3} \mathrm{PPh}^{-}\right)$and bis(2-ethyl hexyl) phosphate (BEH-). More traditional anions such as bis(trifluoromethanesulfonyl) amide $\left(\mathrm{NTf}_{2}^{-}\right)$and bromide (Br-) were also investigated.

Experiments were conducted at various loads to assess the IL film forming abilities. The results suggest that the structure of the anion is important in forming a surface film that reduces the friction and wear of the aluminium disk. At $30 \mathrm{~N}$ five of the six ILs tested showed a $30-90 \%$ reduction in wear, as determined from wear scar depth measurements, compared to fully formulated diesel oil. The IL lubricant with a diphenyl phosphate anion achieved the lowest wear coefficient, showing a better performance than a typical fluorine-containing $\mathrm{IL}$ anion, $\mathrm{NTf}_{2}$. To further investigate wear mechanisms and surface interactions the wear scars were analysed using a scanning electron microscope (SEM) and energy dispersive spectroscopy (EDS).
\end{abstract}

Keywords: ionic liquids, phosphonium, phosphorus anions, phenyl rings, lubricants, tribology, wear test, SEM, EDS. 


\section{Introduction}

The use of aluminium alloys in technical applications is increasing due to their high strength to weight ratio, corrosion resistance and high thermal conductivity [1-3]. Unfortunately, aluminium alloys perform poorly in moving contact as adhesive wear and seizing is likely to occur [4]. For many current applications this means aluminium cannot be used unless it is coated with a wear protecting material, increasing the cost and complexity of production. It would be advantageous for certain applications if suitable lubricants were developed such that steel could move in contact with aluminium without causing excessive wear.

According to lubricant theory, at low loads oil additives with long polar molecules that are adsorbed onto the surface of moving parts work well to reduce friction and wear [5]. Researchers have shown that as the alkyl chain length of an imidazolium ionic liquid is increased the wear and friction between steel and aluminium are reduced $[6,7]$. At increased loads extreme pressure additives in oils, such as zinc-dialkyl-dithiophosphate (ZDDP) for steels, are thought to react and breakdown in the presence of the fresh metal surfaces as a result of the increased temperature and pressure. These reactions form low friction layers, called extreme pressure (EP) layers, which reduce wear and friction. Unfortunately ZDDP has been shown to be incompatible with aluminium alloys as the film it forms can break up to form abrasive particles and a viable alternative is yet to be found $[6,8]$. It has been suggested that the presence of elements such as phosphorus, fluorine, sulphur, boron, oxygen and nitrogen may be important for the formation of extreme pressure layers on aluminium alloy surfaces $[2,4,9,10]$. However, depending on the IL structure, they can also lead to severe tribocorrosion [9].

Most common salts have very high melting points, for instance sodium chloride melts at $801^{\circ} \mathrm{C}$. This high melting point is due to the strong electrostatic forces between the ions, each of which has a strong localised charge. Due to the structure of their molecules the charges on the ions of an IL are much more diffuse and so the electrostatic forces between the anion and cation are reduced such that they exhibit low melting points. Initial interest in ILs focused on their use as electrolytes and as non-volatile solvents for synthesis and chemical reactions but researchers are now investigating other suitable applications, such as lubricants and anti-corrosion coatings and inhibitors [11, 12]. The specific properties of ILs that make them suitable as prospective lubricants are their low volatility, so that they can be used in reduced pressure applications and their non-flammability and thermal stability, meaning they will be able to safely withstand increased temperatures involved when there is high friction. Since ILs have good solubility with organic compounds they can be used with current oils and additives and there is no need for detergents, defoamers or anti-oxidants to improve their compatibility $[13,14]$. Another of the main attractions of ILs is the variety of molecules that can be used; one estimate is that there is something in the order of a million combinations available, each with its own unique properties [15]. This means that ILs may be highly tuneable for a particular application, particularly with respect to surface interactions. ILs and their 
production methods are also considered to be more environmentally friendly when compared to current alternative solvents and electrolytes and it is hoped that this will be the case for many new applications [14].

Ye et al. [16] were the first to assess the performance of an IL as a lubricant for various systems and interest has been increasing ever since [17]. Current research on ILs as lubricants is aimed at identifying those that will improve the wear performance of various systems, including aluminium in contact with steel and identifying the tribochemical reactions at the surface. For the steelaluminium system, researchers have investigated ILs with various cations, such as imidazoliums [13, 14, 16, 18, 19], pyridiniums [13], ammoniums [14] and phosphoniums [4], and various anions, such as $\mathrm{BF}_{4}, \mathrm{PF}_{6}$, triflate, tosylate and $\mathrm{NTf}_{2}$.It has been suggested that alkyl chain length, polarity and the elements present are important factors affecting the anti-wear performance of an IL [2, 3, $7,9,15]$.

Of the ILs tested thus far for the aluminium/steel system the vast majority have included fluorine-containing anions, the only exception being the tosylate anion $\left(\mathrm{CH}_{3} \mathrm{C}_{6} \mathrm{H}_{4} \mathrm{SO}_{3}\right)$, which gave mixed results [7]. In this study the wear performance in a pin-on-disk test of ILs with a trihexyl(tetradecyl) phosphoniumcation $\left(\mathrm{P}_{66614}{ }^{+}\right)$and six different anions will be investigated at different wear regimes. Of the six anions to be tested, four have various novel structures as lubricants, such as different alkyl chain lengths, branched alkyl chains and phenyl rings and all contain phosphorus but no fluorine. As a comparison ILs with a fluorine containing $\mathrm{NTf}_{2}$ anion and a bromide anion were also tested. The system studied uses an ISO100Cr6 steel ball on an AA2024 aluminium disk in a rotating pin-on-disk test.

\section{Experimental}

Scheme 1 shows the structures of the ILs tested. The preparation of the ILs with the DPP, DBP, $\mathrm{M}_{3} \mathrm{PPh}$ and $\mathrm{BEH}$ anions is detailed elsewhere [20-22], while Cytec Canada Inc. supplied the ILs with $\mathrm{NTf}_{2}$ and Bromide anions. The diesel oil used as a standard lubricant was a fully formulated $15 \mathrm{~W}-50$ multigrade oil meeting the API CH-4/SL standard.

The wear tests were conducted on a Nanovearotating pin-on-disk tester using $6 \mathrm{~mm}$ ISO100Cr6 steel balls on AA2024 aluminium disks. The disks were lubricated with $0.1 \mathrm{~mL}$ of the IL to be tested. Tests were conducted at loads of 10 , 20 and $30 \mathrm{~N}$ for a distance of $2500 \mathrm{~m}$, with a wear track diameter of $20 \mathrm{~mm}$ and a speed of $0.2 \mathrm{~m} / \mathrm{s}$. The coefficient-of-friction was recorded throughout the tests. On completion of the wear tests the wear depth was measured using a Dektak 150 stylus profilometer and these values were used to calculate the wear coefficient for each IL. Optical micrographs of the 100Cr6 steel balls were acquired using a Nikon Eclipse ME600. For more detailed analysis of the worn aluminium disk surface SEM and EDS results were obtained on a JEOL JSM840A scanning electron microscope.

Table 1 shows values for the viscosity and conductivity of the ILs at $40^{\circ} \mathrm{C}$. 
Cation:

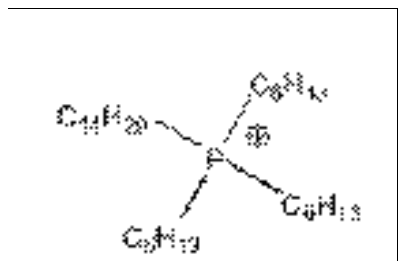

Trihexyl(tetradecyl)phosphonium $\left(\mathrm{P}_{66614}{ }^{+}\right)$

Anions:

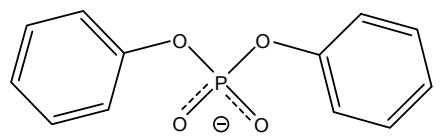

DiphenylPhosphate(DPP')<smiles>CCCCCC(CC)OP(=S)(S)OC(CC)CCCCC</smiles>

Bis-(2-Ethylhexyl)Phosphate Bis 2,4,4-Trimethylpentylphosphinate $\left(\mathrm{BEH}^{-}\right)$

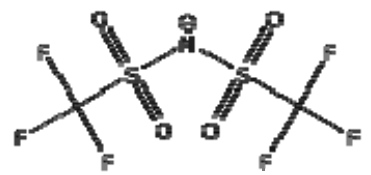

Bis(trifluoromethanesulfonyl) amide $\left(\mathrm{NTf}_{2}^{-}\right)$

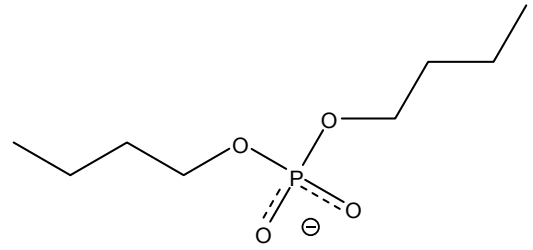

Dibutyl Phosphate(DBP $\left.{ }^{-}\right)$

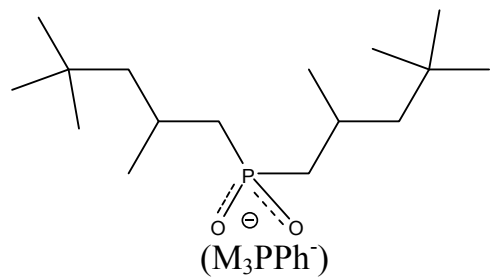

$\mathrm{Br}^{-}$

Bromide

Scheme 1: $\quad$ Ionic liquid structures. 
Table 1: $\quad$ Ionic liquid viscosity and conductivity.

\begin{tabular}{|c|c|c|}
\hline Ionic Liquid & $\begin{array}{c}\text { Viscosity at } 40^{\circ} \mathrm{C} \\
(\mathrm{mPa} . \mathrm{s})\end{array}$ & $\begin{array}{c}\text { Conductivity } \\
\left(\mathrm{S} . c m^{-1} \times 10^{-5}\right)\end{array}$ \\
\hline $\mathrm{P}_{66614} \mathrm{DBP}$ & 130 & 2.0 \\
\hline $\mathrm{P}_{66614} \mathrm{M}_{3} \mathrm{PPh}$ & 120 & 1.8 \\
\hline $\mathrm{P}_{66614} \mathrm{BEH}$ & 260 & 1.2 \\
\hline $\mathrm{P}_{66614} \mathrm{DPP}$ & 210 & 3.2 \\
\hline $\mathrm{P}_{66614} \mathrm{NTf} \mathrm{N}_{2}$ & 140 & 19.7 \\
\hline $\mathrm{P}_{66614} \mathrm{Br}$ & 610 & 2.3 \\
\hline $15 \mathrm{~W} 50 \mathrm{Oil}$ & 340 & 0.000086 \\
\hline
\end{tabular}

\section{Results and discussion}

\subsection{Wear tests}

Figure 1 shows the coefficient of friction (Fig. 1a) and wear coefficient (Fig. 1b) as a function of the load for the six ionic liquids and one fully formulated diesel

(a)

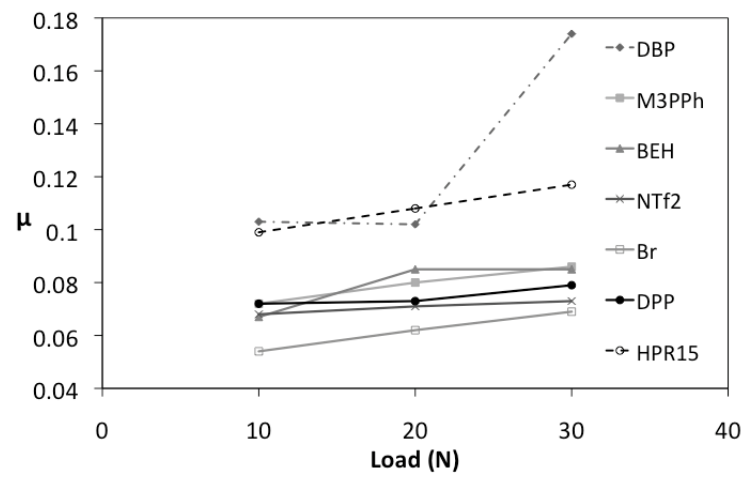

(b)

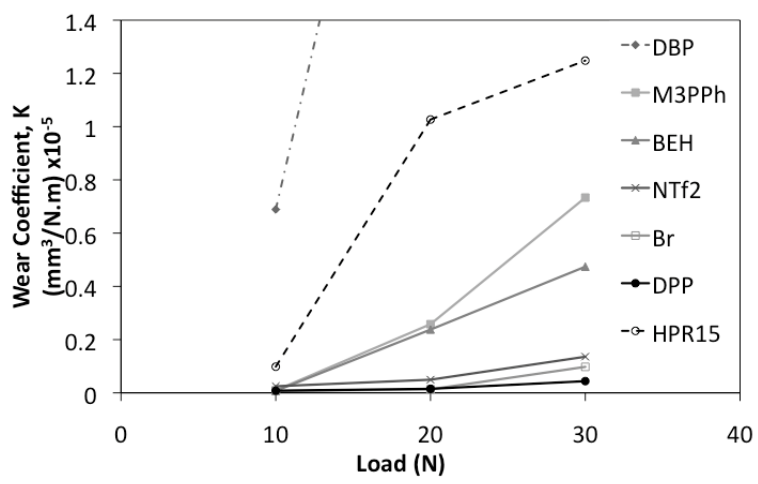

Figure 1: (a) Friction and (b) wear coefficient as a function of load. 
engine oil tested. In both figures it can be seen that the $\mathrm{P}_{66614} \mathrm{DBP}$ and the $15 \mathrm{~W} 50$ engine oil lubricated samples have the highest friction and wear coefficients. In fact, the samples lubricated with $\mathrm{P}_{66614} \mathrm{DBP}$ had such high wear coefficients at loads of $20 \mathrm{~N}\left(3.19 \times 10^{-5}\right)$ and $30 \mathrm{~N}\left(6.71 \times 10^{-5}\right)$ that they were not shown on Figure $1 \mathrm{~b}$ so that the other results could be seen more clearly.

For the other ILs tested the friction coefficients results are much closer, with $\mathrm{P}_{66614} \mathrm{Br}$ showing the lowest friction throughout, and $\mathrm{P}_{66614} \mathrm{DPP}$ and $\mathrm{P}_{66614} \mathrm{NTf}_{2}$ consistently lower than $\mathrm{P}_{66614} \mathrm{BEH}$ and $\mathrm{P}_{66614} \mathrm{M}_{3} \mathrm{PPh}$.

The differences in the wear coefficient (Fig. 1b) are much more marked than the friction coefficients. As mentioned above, the $\mathrm{P}_{66614} \mathrm{DBP}$ lubricated aluminium disk showed severe wear and the samples lubricated with the engine oil had significantly higher wear coefficients than the other samples. Of the remaining ILs the $\mathrm{P}_{66614} \mathrm{BEH}$ and $\mathrm{P}_{66614} \mathrm{M}_{3} \mathrm{PPh}$ showed much higher wear than the $\mathrm{P}_{66614} \mathrm{NTf}_{2}, \mathrm{P}_{66614} \mathrm{Br}$ and $\mathrm{P}_{66614} \mathrm{DPP}$. It can be seen that the aluminium disks lubricated with these latter three ILs resulted in very low wear coefficients. At $30 \mathrm{~N}$ the wear coefficients for $\mathrm{P}_{66614} \mathrm{NTf}_{2}, \mathrm{P}_{66614} \mathrm{Br}$ and $\mathrm{P}_{66614} \mathrm{DPP}$, respectively, are: $0.14 \times 10^{-5}, 0.10 \times 10^{-5}$ and $0.04 \times 10^{-5} \mathrm{~mm}^{3} / \mathrm{N} . \mathrm{m}$.

\subsection{Scanning electron microscopy (SEM)}

Figure 2 shows SEM images of the wear scars on the aluminium disk and optical images of the scar on the steel balls for all the systems tested.

The pictures and spectra are shown in order of highest to lowest wear coefficient (see Figure 1b). For the sample lubricated with $\mathrm{P}_{66614} \mathrm{DBP}$ the wear scars on the aluminium disk and the steel ball show much evidence of adhesive wear as there appears to be aluminium stuck to the surface of the steel ball. Moving through the samples the amount of adhesion can be seen to be reducing and on the $\mathrm{P}_{66614} \mathrm{Br}$ and $\mathrm{P}_{66614} \mathrm{DPP}$ lubricated samples there appears to be no adhesion occurring. On close inspection of the steel ball sample for the $\mathrm{P}_{66614} \mathrm{Br}$ sample there are signs of what may be pitting corrosion above and below the wear scar, indicating that the steel ball may be corroding in the presence of the IL. This may explain why this sample showed the lowest coefficient of friction (see Figure 1a), as the corrosion product from the steel may have been forming a low friction film between the steel ball and the aluminium disk.

\subsection{Energy dispersive X-ray spectroscopy (EDS)}

Figure 3 shows EDS spectra taken of the IL lubricated aluminium wear scars tested at $30 \mathrm{~N}$. For the disks lubricated with $\mathrm{P}_{66614} \mathrm{DBP}$ and $\mathrm{P}_{66614} \mathrm{Br}$ the spectra show aluminium, oxygen, copper and magnesium from the alloy present, but no sign of any IL components. This does not mean there is not any IL present, as the films formed by ILs may be too thin for EDS to detect. For $\mathrm{P}_{66614} \mathrm{M}_{3} \mathrm{PPh}$ and $\mathrm{P}_{66614} \mathrm{BEH}$ a small amount of phosphorus was detected, suggesting that an adsorbed layer of IL was present. Since these lubricants showed a moderately high wear coefficient, there may be some tribocorrosion occurring, where the IL reacts with the surface to such an extent that it is removed as corrosion product, thus exposing fresh surface to react with. 

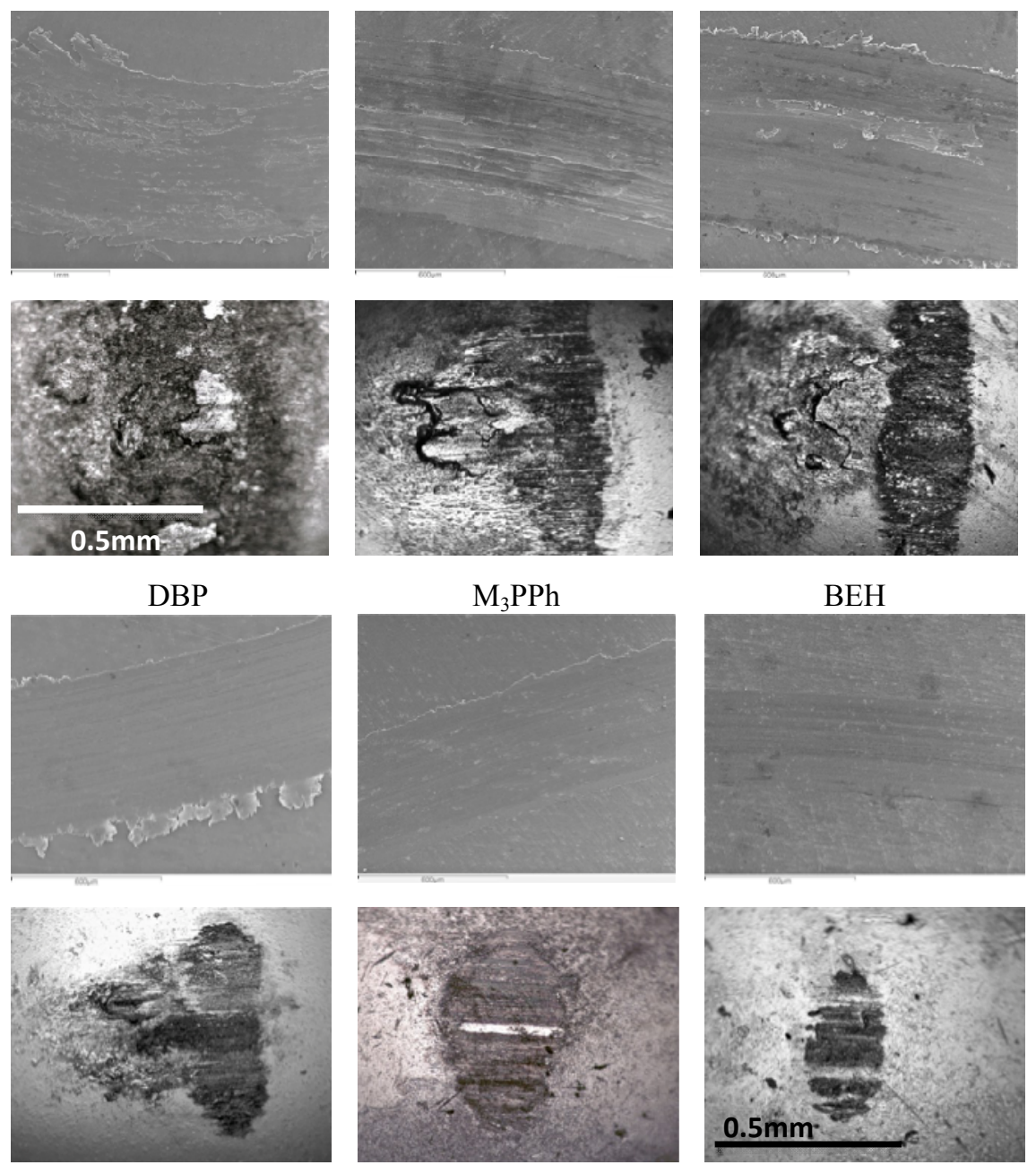

$\mathrm{NTf}_{2}$

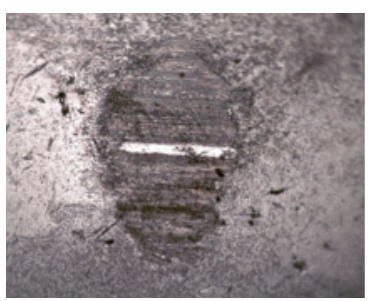

$\mathrm{Br}$

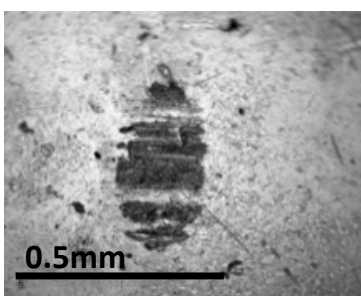

DPP

Figure 2: Wear scars on the aluminium disks and steel balls for the IL lubricated samples tested at $30 \mathrm{~N}$ for $2500 \mathrm{~m}$.

The spectrum for $\mathrm{P}_{66614} \mathrm{NTf}_{2}$ shows the presence of fluorine and sulphur, both components of the IL anion. This suggests that it is the anion that has adsorbed onto the surface of the aluminium. The spectrum for $\mathrm{P}_{66614} \mathrm{NTf}_{2}$ also shows a very high oxygen content, suggesting that the film formed is part of an oxidation reaction. The IL spectrum for the lubricant that showed the lowest wearcoefficient, $\mathrm{P}_{66614} \mathrm{DPP}$, shows the presence of phosphorus on the aluminium surface. This spectrum is similar to that of $\mathrm{P}_{66614} \mathrm{M}_{3} \mathrm{PPh}$ and $\mathrm{P}_{66614} \mathrm{BEH}$, but the IL lubricant resulted in a much lower wear coefficient. In this case the IL may not react with the surface to such an extent that tribocorrosion occurs. Bermudez 


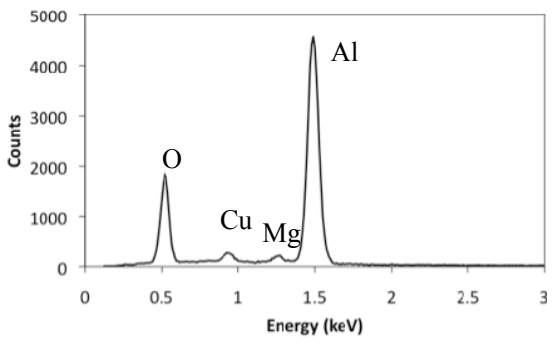

DBP

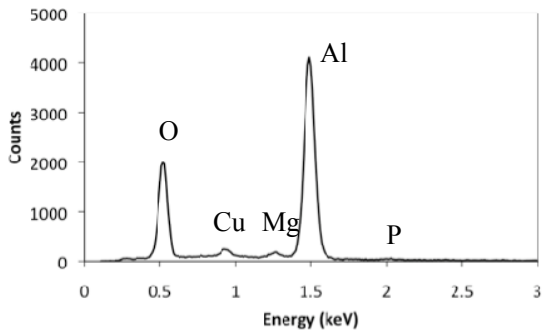

$\mathrm{BEH}$

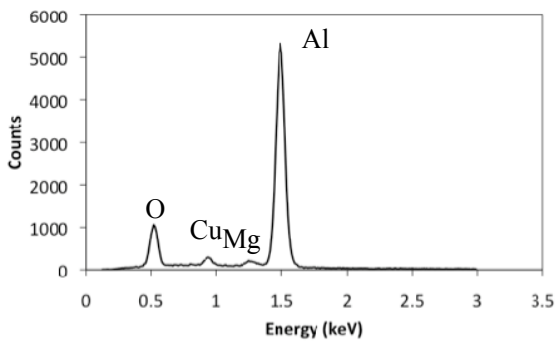

$\mathrm{Br}$

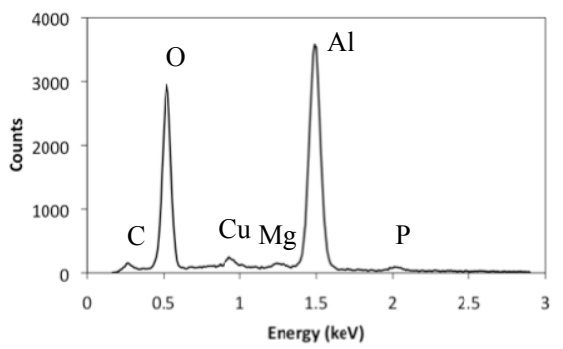

$\mathrm{M}_{3} \mathrm{PPh}$

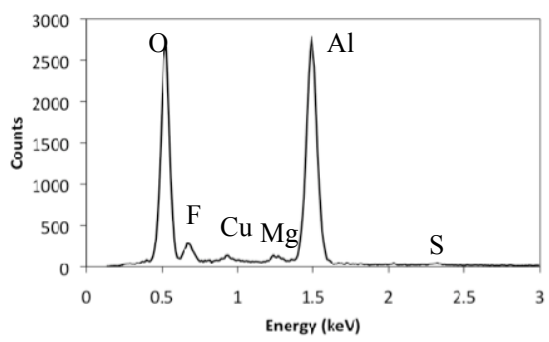

$\mathrm{NTf}_{2}$

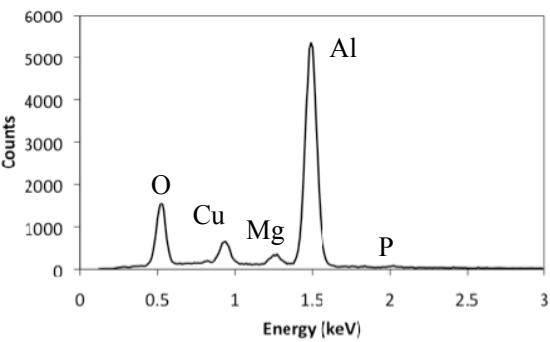

DPP

Figure 3: EDS spectra of wear scars on IL lubricated aluminium disks tested at $30 \mathrm{~N}$.

found that similar ILs had markedly different rates of wear and tribocorrosion, depending on their polarity.

In comparing the performance of the four phosphorus-containing IL lubricants there may be a correlation to their structure (Scheme 1) and viscosity (Table 1). In order from highest to lowest wear coefficient the novel IL lubricants are: $\mathrm{P}_{66614} \mathrm{DBP}, \mathrm{P}_{66614} \mathrm{M}_{3} \mathrm{PPh}, \mathrm{P}_{66614} \mathrm{BEH}$ and $\mathrm{P}_{66614} \mathrm{DPP}$. The DBP anion contains simple alkyl chains and has a viscosity of $130 \mathrm{mPa}$.s. The $\mathrm{M}_{3} \mathrm{PPh}$ anion has short, branched chains and a similar viscosity, $120 \mathrm{mPa}$.s. The BEH anion has long branched chains, and its viscosity is much higher (260 mPa.s). The DPP anion has two phenyl rings present and a similar viscosity to the BEH, 
$210 \mathrm{mPa} . \mathrm{s}$, but a much lower wear coefficient. It has been suggested that the ability of ILs to adsorb onto the surface and form layers is important for lubrication under film-forming conditions [4, 9] and the phenyl rings present in the DPP may influence its film forming ability, since it has achieved such a low wear coefficient. The DPP may be able to form layers on the surface due to surface interactions and/or the ability of the rigid phenyl rings to remain flat. The polarity of the ILs may also play a role and the complex nature of the films formed during wear needs further investigation [9].

\section{Conclusion}

The wear performance of four novel phosphonium based ionic liquids with phosphorus containing anions was assessed for lubricating ISO100Cr6 steel sliding on AA2024 aluminium disks. Their performance was evaluated in comparison to fully formulated diesel engine oil and similar phosphonium ionic liquids containing bromide and $\mathrm{NTf}_{2}$ anions. The performance of these novel ILs varied widely, with the $\mathrm{P}_{66614} \mathrm{DPP}$ lubricated sample achieving the lowest wear coefficient and the $\mathrm{P}_{66614} \mathrm{DBP}$ the highest. It is suggested that the phenyl rings in the structure of $\mathrm{P}_{66614} \mathrm{DPP}$ may be beneficial in forming a layer structure on the contact surfaces that reduces friction and wear.

\section{References}

[1] Jiménez, A.-E. \&Bermúdez, M.-D., Ionic liquids as lubricants for steelaluminum contacts at low and elevated temperatures.Tribology Letters, 2007. 26(1): pp. 53-60.

[2] Mu, Z., Wang, X., Zhang, S., Liang, Y., Bao, M., \&Liu, W., Investigation of tribological behavior of Al--Si alloy against steel lubricated with ionic liquids of 1-diethylphosphonyl-n-propyl-3- alkylimidazolium tetrafluoroborate. Journal of Tribology, 2008. 130(3): pp. art. no. 034501.

[3] Qu, J., Blau, P.J., Dai, S., Luo, H., Meyer III, H.M., \&Truhan, J.J., Tribological characteristics of aluminum alloys sliding against steel lubricated by ammonium and imidazolium ionic liquids. Wear, 2009. 267(58): pp. 1226-1231.

[4] Liu, X., Zhou, F., Liang, Y., \&Liu, W., Tribological performance of phosphonium based ionic liquids for an aluminum-on-steel system and opinions on lubrication mechanism. Wear, 2006. 261(10): pp. 1174-1179.

[5] Kenbeek, D. \&Buenemann, T.F., Lubricant additives: chemistry and applications. 1st ed, ed. L.R. Rudnick. 2003, Boca Raton, FL: CRC Press.

[6] Mu, Z., Zhou, F., Zhang, S., Liang, Y., \&Liu, W., Effect of the functional groups in ionic liquid molecules on the friction and wear behavior of aluminum alloy in lubricated aluminum-on-steel contact.Tribology International, 2005. 38(8): pp. 725-731.

[7] Jiménez, A.E., Bermúdez, M.D., Iglesias, P., Carrión, F.J., \&MartínezNicolás, G., 1-N-alkyl -3-methylimidazolium ionic liquids as neat 
lubricants and lubricant additives in steel-aluminium contacts. Wear, 2006. 260(7-8): pp. 766-782.

[8] Nicholls, M.A., Do, T., Norton, P.R., Kasrai, M., \&Bancroft, G.M., Review of the lubrication of metallic surfaces by zinc dialkyldithiophosphates. Tribology International, 2005. 38(1): pp. 15-39.

[9] Bermúdez, M.D. \&Jiménez, A.E., Surface interactions and tribochemical processes in Ionic Liquid lubrication of aluminium-steel contacts.International Journal of Surface Science and Engineering, 2007. 1(1): pp. 100-10.

[10] Hu, L., Chen, J., Liu, W., Xue, Q., \&Kajdas, C., Investigation of tribochemical behavior of Al-Si alloy against itself lubricated by amines. Wear, 2000. 243(1-2): pp. 60-67.

[11] Howlett, P.C., Zhang, S., MacFarlane, D.R., \&Forsyth, M., An investigation of a phosphinate-based ionic liquid for corrosion protection of magnesium alloy AZ31.Australian Journal of Chemistry, 2007. 60(1): pp. 43-46.

[12] Zhang, Q.B. \&Hua, Y.X., Corrosion inhibition of mild steel by alkylimidazolium ionic liquids in hydrochloric acid.Electrochimica Acta, 2009. 54(6): pp. 1881-1887.

[13] Jiménez, A.E., Bermúdez, M.D., Carrión, F.J., \&Martínez-Nicolás, G., Room temperature ionic liquids as lubricant additives in steel-aluminium contacts: Influence of sliding velocity, normal load and temperature.Wear, 2006. 261(3-4): pp. 347-359.

[14] Qu, J., Truhan, J., Dai, S., Luo, H., \&Blau, P., Ionic liquids with ammonium cations as lubricants or additives.Tribology Letters, 2006. 22(3): pp. 207-214.

[15] Yagi, T., Sasaki, S., Mano, H., Miyake, K., Nakano, M., \&Ishida, T., Lubricity and chemical reactivity of ionic liquid used for sliding metals under high-vacuum conditions.Proceedings of the Institution of Mechanical Engineers, Part J: Journal of Engineering Tribology, 2009. 223(7): pp. 1083-1090.

[16] Ye, C., Liu, W., Chen, Y., \&Yu, L., Room-temperature ionic liquids: a novel versatile lubricant.Chemical Communications, 2001(21): pp. $2244-$ 2245.

[17] Bermúdez, M.D., Jiménez, A.E., Sanes, J., \&Carrión, F.J., Ionic liquids as advanced lubricant fluids. Molecules, 2009. 14(8): pp. 2888-2908.

[18] Chen, Yunxia, Ye, Chengfeng, Wang, Haizhong, Liu, and Weimin, Tribological performance of an ionic liquid as a lubricant for steel/aluminium contacts.Journal of Synthetic Lubrication, 2003. 20(3): pp. 217-225.

[19] Mistry, K., Fox, M.F., \& Priest, M., Lubrication of an electroplated nickel matrix silicon carbide coated eutectic aluminium-silicon alloy automotive cylinder bore with an ionic liquid as a lubricant additive.Proceedings of the Institution of Mechanical Engineers, Part J: Journal of Engineering Tribology, 2009. 223(3): pp. 563-569. 
[20] Sun, J., Howlett, P.C., MacFarlane, D.R., Lin, J., \& Forsyth, M., Synthesis and physical property characterisation of phosphonium ionic liquids based on $\mathrm{P}(\mathrm{O})_{2}(\mathrm{OR})_{2}^{-}$and $\mathrm{P}(\mathrm{O})_{2}(\mathrm{R})_{2}{ }^{-}$anions with potential application for corrosion mitigation of magnesium alloys.Electrochimica Acta, 2008. 54(2): pp. 254-260.

[21] McNulty, J., Cheekoori, S., Bender, T.P., \& Coggan, J.A., A pronounced anionic effect in the Pd-catalyzed Buchwald-Hartwig animation reaction revealed in phosphonium salt ionic liquids.European Journal of Organic Chemistry, 2007(9): pp. 1423-1428.

[22] Bradaric, C.J., Downard, A., Kennedy, C., Robertson, A.J., \& Zhou, Y., Industrial preparation of phosphonium ionic liquids.Green Chemistry, 2003. 5(2): pp. 143-152. 